\title{
Myocardial Malondialdehyde and Uric Acid Release After Short-Lasting Coronary Occlusions During Coronary Angioplasty: Potential Mechanisms for Free Radical Generation
}

\author{
I. K. De Scheerder, MD, PhD, A. M. M. van de Kraay, MD, J. M. J. Lamers, PhD, \\ J. F. Koster, PhD, J.W. de Jong, PhD, and P.W. Serruys, MD, PhD
}

$\mathrm{T}$ he stunned myocardium has recently become the focus of considerable interest because of its potential role in negating the benefits of reperfusion. A critical but still unresolved issue relates to the mechanism responsible for this contractile abnormality. In recent years an increasing number of studies have provided indirect evidence that postischemic myocardial dysfunction may be mediated in part by the generation of reactive oxygen species, such as superoxide radical, hydrogen peroxide and hydroxyl radical. These oxygen-free radicals could arise from various sources, such as hypoxanthine conversion by xanthine oxidase, catecholamine degradation and mitochondrial electron transport. Direct evidence of injury by free radicals has yet to be shown in the human heart, but many studies of other mammals have linked reactive oxygen metabolites with myocardial injury. ${ }^{1-5}$ During myocardial ischemia, xanthine dehydrogenase (which appears to be located in the endothelial cells) ${ }^{6}$ is converted to xanthine oxidase, an enzyme that produces superoxide radical, hydrogen peroxide and uric acid from hypoxanthine or xanthine and molecular oxygen. ${ }^{7}$ At the same time, ischemia is associated with rapid catabolism of adenosine triphosphate. This degradation of adenosine triphosphate causes an efflux of breakdown products that are able to pass through the cell membrane, resulting in an accumulation of hypoxanthine, 1 of 2 substrates for xanthine oxidase. The other substrate (molecular oxygen) is provided by reperfusion, which results in a burst of free-radical generation. ${ }^{8}$ Thesc free radicals initiate chain reactions causing peroxidative breakdown of polyunsaturated fatty acids in the membrane bilayer. ${ }^{9-12}$ The interaction among oxygen-free radicals with polyunsaturated fatty acids has been described as lipid peroxidation and can be measured by formation of malondialdehyde. Until recently, the assessment of alterations in myocardial metabolism in humans early after short and repetitive occlusions of a major coronary artery has not been feasible. However, percutaneous transluminal coronary angioplasty provides a unique opportunity to study the time course of these metabolic changes during transient interruption of coronary flow by the balloon-occlusion sequence in patients with 1-vessel disease and without angi-

From the Thoraxcenter and Department of Biochemistry 1, Erasmus University Rotterdam, 3000 DR Rotterdam, the Netherlands. Manuscript received August 29, 1990; revised manuscript received and accepted April 10, 1991. ographically demonstrable collateral circulation. ${ }^{13-16}$ In this report we studied the production of hypoxanthine, urate and malondialdehyde during percutaneous transluminal coronary angioplasty.

All patients met the following criteria: a brief history of angina pectoris ( $<1$ year), an isolated obstructive lesion in the left anterior descending coronary artery, and an accessible stenosis of $<1 \mathrm{~cm}$ in length. All patients were candidates for coronary artery bypass graft surgery because of disabling angina, but were selected for angioplasty rather than surgery because of their anatomy. Ten patients $(8$ men and 2 women, aged 37 to 72 years) were studied. Of these, 4 were in New York Heart Association class II, 5 in class III and 1 in class IV. In all, the ejection fraction was $>50 \%$ and none of them had wall motion abnormalities on their left ventriculograms at rest. Four consecutive transluminal dilatations of 90 seconds each with deflation intervals of 3 minutes were performed. All patients gave informed consent and there were no complications directly related to the research procedure.

A Pepine catheter was inserted in the coronary sinus with the end-hole positioned at the origin of the great cardiac vein for blood sampling. Arteriovenous differences of blood hypoxanthine, urate and malondialdehyde were determined at baseline immediately after each balloon deflation and, finally, 5 and 15 minutes after the percutaneous transluminal coronary angioplasty procedure.

HYPOXANTHINE AND URATE: Great cardiac vein and femoral arterial blood samples were collected in heparinized tubes with equal volumes of cold $154 \mathrm{mM}$ sodium chloride, containing $20 \mu \mathrm{M}$ dipyridamole (Boehringer, Ingelheim, Federal Republic of Germany), and $10 \mu M$ erythro-9-(2-hydroxy-3-nonyl) adenine hydrochloride (Wellcome, London, Great Britain). These drugs were used to inhibit adenosine uptake and breakdown. Mixtures were centrifuged in the cold. The supernatant fluids were stored at $-80^{\circ} \mathrm{C}$. On the day of analysis, these were thawed and mixed with cold $8 \%$ perchloric acid. Hypoxanthine and urate were assayed by high-performance liquid chromatography using the method of Huizer et al. ${ }^{17}$

MALONDIAIDEHYDE: After separation of blood cells by centrifugation at 0 to $4^{\circ} \mathrm{C}$, the plasma was frozen in liquid nitrogen and stored at $-80^{\circ} \mathrm{C}$. The malon- 


\begin{tabular}{|c|c|c|c|c|c|c|}
\hline & 1 & 2 & 3 & $t$ & 5 & 6 \\
\hline $\mathrm{BL}$ & -0.224 & 0.473 & -0.267 & -0.446 & -0.160 & -0.320 \\
\hline Post l & 0.169 & 0.648 & 0.805 & 6.392 & 0.649 & 1.990 \\
\hline Post 2 & 2.606 & 0.522 & 2.367 & 28.410 & 0.747 & 1.117 \\
\hline Post 3 & 1.941 & 0.891 & 2.429 & 23.934 & 3.039 & 1.385 \\
\hline Post 4 & 0.815 & 3.070 & 4.163 & 2.080 & 0.467 & 1.510 \\
\hline R5 & 0.542 & -0.069 & 5.940 & 0.938 & 0.562 & -0.042 \\
\hline \multirow[t]{2}{*}{ R15 } & 0.336 & 0.205 & 6.114 & 0.415 & -0.521 & -0.364 \\
\hline & 7 & 8 & 9 & 10 & \multicolumn{2}{|c|}{ Mean \pm SEM } \\
\hline $\mathrm{BL}$ & 0.410 & 0.447 & 0.847 & 0.587 & \multicolumn{2}{|c|}{$0.14 \pm 0.15$} \\
\hline Post 1 & 3.250 & \multirow{2}{*}{$\begin{array}{l}0.467 \\
1.740\end{array}$} & \multirow{2}{*}{5.968} & 0.273 & \multicolumn{2}{|c|}{$2.06 \pm 0.75$} \\
\hline Post 2 & 3.160 & & & \multirow{2}{*}{$\begin{array}{l}30.910 \\
27.060\end{array}$} & \multicolumn{2}{|c|}{$7.45 \div 3.72$} \\
\hline Post 3 & 1.500 & 4.010 & $\begin{array}{l}2.939 \\
2.160\end{array}$ & & \multicolumn{2}{|c|}{$6.83 \pm 3.13$} \\
\hline Post 4 & -0.978 & 0.840 & 1.160 & 7.441 & \multicolumn{2}{|c|}{$2.06 \pm 0.75$} \\
\hline R5 & -0.010 & 0.800 & -0.660 & 5.900 & \multicolumn{2}{|c|}{$1.39 \pm 0.76$} \\
\hline R15 & -0.460 & -0.300 & -0.440 & -0.460 & 0.45 & $5 \pm 0.63$ \\
\hline \multicolumn{7}{|c|}{ 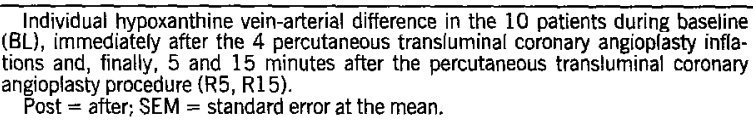 } \\
\hline
\end{tabular}

dialdehyde content of the plasma samples was measured in the presence of $100 \mu \mathrm{M}$ ethylene diaminetetraacetic acid as described by Jackson et al. ${ }^{18}$ The extinction coefficient of the thiobarbituric acid product was taken as $1.56 \times 10^{5} \mathrm{M}-1 \mathrm{~cm}-1$ for all calculations of the malondialdehyde content.

Values are reported as mean \pm standard error of the mean. Comparison between results before and after percutaneous transluminal coronary angioplasty and occlusion conditions were evaluated using analysis of variance for repeated measurements. When overall significance was found, multiple comparisons were considered significantly different at $p<0.05$. The relation between uric acid and malondialdehyde arteriovenous difference was evaluated by linear regression analysis.

HYPOXANTHINE PRODUCTION: We studied hypoxanthine production by measuring vein arterial hypoxanthine concentration. Baseline value was $+0.14 \pm 0.15$ $\mu M$. After the first dilatation, vein-arterial hypoxanthine concentration significantly increased to $+2.06 \pm 0.75 \mu M(p<0.01$ vs baseline $)$, after the second to $+7.45 \pm 3.7$, after the third to $+6.83 \pm 3.13$, and after the fourth to $+2.06 \pm 0.75 \mu M$. Five minutes after the fourth occlusion the vein-arterial difference remained significantly increased $(+1.39 \pm 0.76$; $p<0.05$ vs baseline), whereas after 15 minutes recovery vein-arterial difference returned to baseline values $(+0.45 \pm 0.63 \mu M ; p=$ not significant $[N S]$ vs baseline). Detailed hypoxanthine production figures of the 10 patients are listed in Table $I$.

URATE PRODUCTION: We observed a baseline urate vein-arterial difference of $+2.34 \pm 3.12 \mu M$. After the first dilatation, urate vein-arterial difference

\begin{tabular}{|c|c|c|c|c|c|c|}
\hline & 1 & 2 & 3 & 4 & 5 & 6 \\
\hline $\mathrm{BL}$ & 10 & 7 & 6 & 21 & -7 & 4 \\
\hline Postinfl 1 & -15 & 2 & 6 & 5 & 11 & 5 \\
\hline Postinfl 2 & -1 & 4 & -2 & 2 & 5 & -2 \\
\hline Postinfl 3 & -5 & 6 & 2 & 6 & 19 & 10 \\
\hline Postinfl 4 & 5 & 11 & 29 & 6 & -28 & 6 \\
\hline R5 & -2 & 40 & 43 & 17 & -7 & 2 \\
\hline \multirow[t]{2}{*}{$\mathrm{R} 15$} & -4 & 5 & 17 & 4 & -14 & -3 \\
\hline & 7 & 8 & 9 & 10 & \multicolumn{2}{|c|}{ Mean \pm SEM } \\
\hline BL & -6 & -9 & 6.4 & -9 & 2.34 & 3.12 \\
\hline Postinfl 1 & -2 & -3 & 2 & 3.7 & 1.47 & 2.22 \\
\hline Postinfl 2 & 3 & 3.6 & 5 & -2 & 1.56 & 0.95 \\
\hline Postinfl 3 & 8 & 9 & -11 & 13.8 & 5.78 & 2.76 \\
\hline Postinfl 4 & 18 & 19.8 & -17 & 30 & 7.98 & 5.87 \\
\hline R5 & 15 & 29 & -14 & 52 & 17.50 & 7.23 \\
\hline R15 & 3 & 10 & -13 & 8.2 & 1.32 & 3.12 \\
\hline
\end{tabular}

TABLE III Vein-Arterial Malondialdehyde Difference in the 10 Patients

\begin{tabular}{|c|c|c|c|c|c|c|}
\hline & 1 & 2 & 3 & 4 & 5 & 6 \\
\hline $\mathrm{BL}$ & -0.32 & -0.39 & 0.96 & 1.88 & -1.67 & 1.30 \\
\hline Post 1 & 0.30 & 1.07 & 0.83 & -0.55 & -1.04 & 1.52 \\
\hline Post 2 & 1.27 & -0.64 & -0.1 & 0.79 & 1.07 & -0.43 \\
\hline Post 3 & -1.29 & -0.65 & 3.47 & 2.73 & -0.92 & 1.06 \\
\hline Post 4 & -1.40 & -1.00 & 2.67 & 2.38 & 1.5 & -1.42 \\
\hline R5 & -1.73 & 1.35 & 3.5 & 3.22 & -1.48 & -2.36 \\
\hline \multirow[t]{2}{*}{ R15 } & -1.07 & 0.23 & -0.96 & -0.23 & -0.37 & 1.39 \\
\hline & 7 & 8 & 9 & 10 & \multicolumn{2}{|c|}{ Mean \pm SEM } \\
\hline $\mathrm{BL}$ & 0.10 & -1.88 & -0.47 & -1.71 & \multicolumn{2}{|c|}{$-0.22 \pm 0.41$} \\
\hline Post 1 & 0.29 & 1.19 & -1.94 & 1.73 & \multicolumn{2}{|c|}{$0.34 \pm 0.37$} \\
\hline Post 2 & 0.66 & 1.37 & 0.31 & 0.23 & \multicolumn{2}{|c|}{$0.45 \pm 0.22$} \\
\hline Post 3 & 0.93 & 3.60 & 2.44 & -1.44 & \multicolumn{2}{|c|}{$0.99 \pm 0.63$} \\
\hline Post 4 & 1.01 & 1.68 & 2.22 & 3.85 & \multicolumn{2}{|c|}{$1.15 \pm 0.58$} \\
\hline R5 & 0.59 & 3.73 & 5.30 & 5.28 & \multicolumn{2}{|c|}{$1.74 \pm 0.91$} \\
\hline $\mathrm{R} 15$ & -0.63 & 1.06 & -0.96 & 0.86 & \multicolumn{2}{|c|}{$-0.07 \pm 0.29$} \\
\hline
\end{tabular}

was $+1.47 \pm 2.22 \mu M$ (NS vs baseline), after the second $+1.56 \pm 0.95 \mu M$ (NS vs baseline), after the third $+5.78 \pm 2.76 \mu M(p<0.01$ vs baseline $)$, and after the fourth $+7.98 \pm 5.87$ ( $p<0.01$ vs baseline). After 5minute reoxygenation, vein-arterial urate difference further increased to $+17.50 \pm 7.23 \mu M(p<0.001)$, whereas 15 minutes after the last inflation, vein-arterial urate difference normalized $(+1.32 \pm 3.12 \mu M$, NS). Detailed urate production figures of the $10 \mathrm{pa-}$ tients are listed in Table II.

MALONDIALDEHYDE PRODUCTION: Before percutaneous transluminal coronary angioplasty, vein-arterial malondialdehyde was $-0.22 \pm 0.41 \mu M$, after the first dilatation it increased to $+0.34 \pm 0.37 \mu M$ (NS vs baseline), after the second occlusion to $+0.45 \pm 0.22 \mu M(p<0.05$ vs baseline $)$, after the third to $+0.99 \pm 0.63 \mu M(p<0.01$ vs baseline $)$, and after the fourth to $+1.15 \pm 0.58 \mu M(p<0.01$ vs base- 
line). After 5-minute reperfusion, vein-arterial malondialdehyde further increased to $1.74 \pm 0.91 \mu \mathrm{M}$ ( $p<0.01$ vs baseline). Finally, after 15 minutes it returned to baseline levels $(-0.07 \pm 0.29 \mu M, N S)$. Detailed malondialdehyde production figures of the 10 patients are shown in Table III.

The present data show that short repetitive coronary total occlusions of the left anterior descending artery during percutaneous transluminal coronary angioplasty procedure lead to a significant increase of great cardiac vein-arterial concentrations of hypoxanthine, uric acid and malondialdehyde (Figure 1). For malondialdehyde,

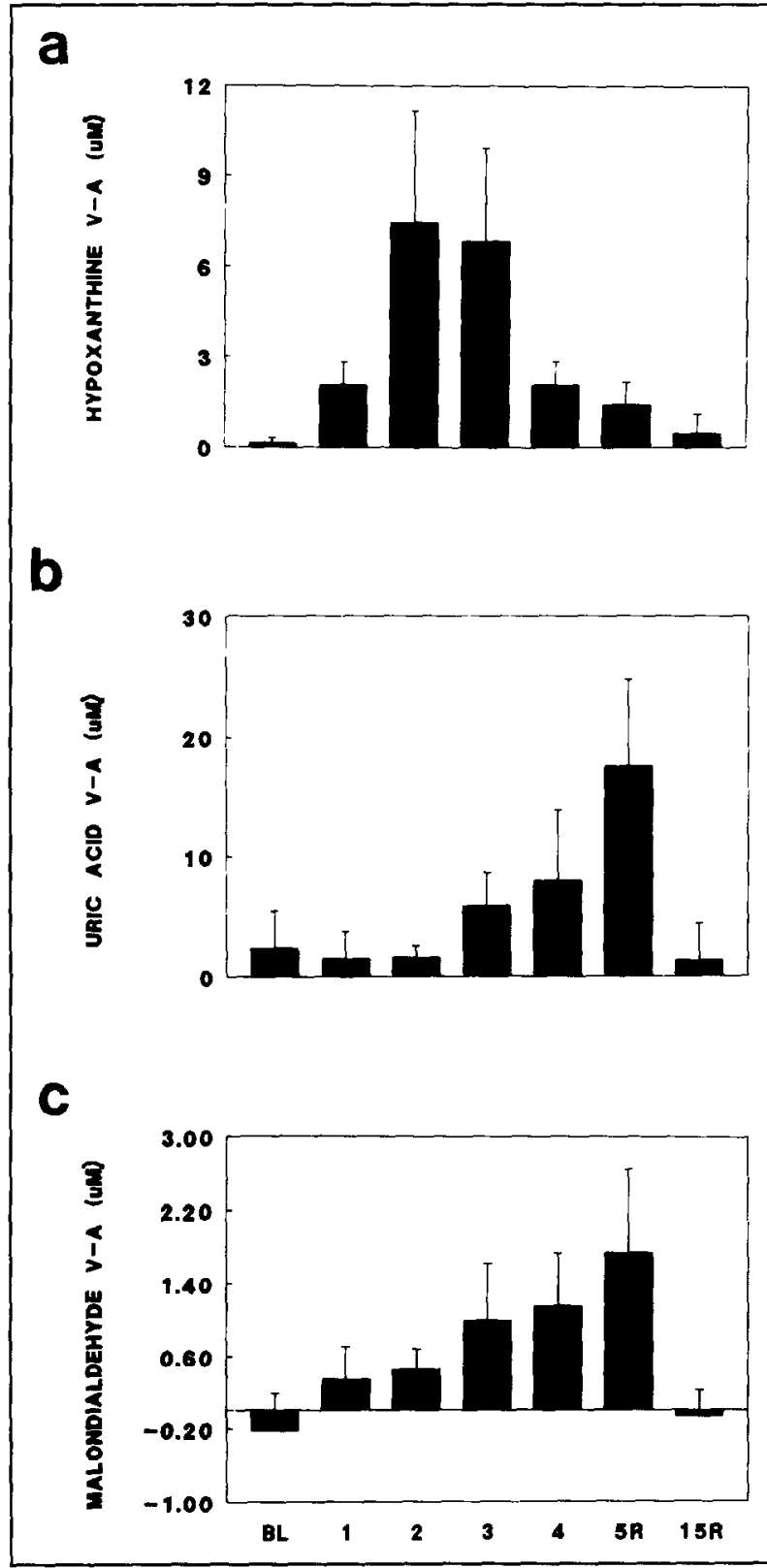

FIGURE 1. Hypoxanthine (a), uric acid (b) and malondialdehyde (c) vein-arterial ( $V-A)$ differences during baseline (BL), immediately after the 4 percutaneous transhuminal coronary angioplasty inflations and, finally, 5 and 15 minutes after the percutaneous transhuminal coronary angioplasty procedure $(5 R, 15 R)$. vein-arterial difference showed a progressive increase that peaked 5 minutes after the last inflation. The regression analysis between uric acid and malondialdehyde vein-arterial difference was not significant $(r=0.34$, NS), which also suggests that other oxygen-free radical sources may play a role. On average, uric acid veinarterial difference parallels that of malondialdehyde, in contrast to hypoxanthine vein-arterial difference, which peaked around the second and third inflations. Production of malondialdehyde reflects lipid peroxidation, which suggests production of oxygen-free radicals, so the production of malondialdehyde in this model likely results from the generation of oxygen-free radicals. ${ }^{9-12}$ However, malondialdehyde is only one of many products of lipid peroxidation. The reaction between thiobarbituric acid and malondialdehyde produces a pink color that can be measured by spectrophotometry. This assay has been used to study circulating lipoperoxides in many diseases. ${ }^{19-21}$ The assay used in this study usually gives higher malondialdehyde concentrations than are actually present because not only is malondialdehyde measured but also other aldehydes. Furthermore, it measures both preexisting malondialdehyde and all other substances that give rise to malondialdehyde during the assay (in vitro and in vivo). In addition, several chemical species other than malondialdehyde can react with thiobarbituric acid to produce a pink to red color. ${ }^{22}$ This relative lack of specificity of the thiobarbituric assay has been criticized, but malondialdhyde appears to be produced in a relatively constant proportion to the rate of lipid peroxidation $^{23}$; thus, when all samples from 1 patient are assayed simultaneously, the results should reflect the degree of peroxidation. There are several potential sources of oxygen-free radicals during human myocardial ischemia/reperfusion. ${ }^{1,24}$ First, ischemia itself may produce cytotoxic free radicals as a result of reactions involving mitochondrial electron transfer ${ }^{25}$ after catecholamine degradation by monoamine oxidases, autooxidation or, what is more likely at physiological $\mathrm{pH}$, metal-catalyzed oxidation. ${ }^{1,26}$ Second, the univalent reduction of oxygen by activated neutrophils, ${ }^{1,27}$ though an important source of radicals, is probably not relevant in transient ischemia because it is likely that the chemotactic factors required to promote neutrophil migration into ischemic tissue require several hours for full expression. ${ }^{28}$ Third, the action of endothelial xanthine oxidase on purine metabolites accumulated during ischemia is another possible system for generating oxygen-free radicals. ${ }^{19,29,30}$ Published data on xanthine oxidase in human myocardium are controversial, ${ }^{30}$ perhaps owing to the fact that the enzyme can inactivate itself. ${ }^{31} \mathrm{We}$ found urate production after angioplasty, ${ }^{15}$ but not by isolated perfused human heart. ${ }^{30}$ The parallel production of urate and malondialdehyde after repetitive coronary occlusions in the angioplastic procedure suggests the possible importance of this 
pathway in the production of oxygen-free radicals in the human ischemic heart. These radicals may play a role in the persistence of regional left ventricle dysfunction after reperfusion.

Acknowledgment: We wish to thank Dick H. W. Dekkers and Selma Nieukoop for their expert technical assistance.

1. Bolli R. Oxygen-derived free radicals and postischemic myocardial dysfunction ("stunned myocardium"). J Am Coll Cardiol 1988;12:239-249.

2. Jolly SR, Kane WJ, Bailie MB, Abrams GD, Lucchesi BR. Canine myocardial reperfusion injury: its reduction by the combined administration of superoxide dismutase and catalase. Circ Res 1984;54:277-285.

3. Przyklenk K, Kloner RA. Superoxide dismutase plus catalase improve contractile function in the canine model of the "stunned" myocardium. Circ Res 1986;58:148-156.

4. Gross GJ, Farber NE, Hardman HF, Warltier DC. Beneficial actions of superoxide dismutase and catalase in stunned myocardium of dogs. Am J Physiol 1986:250:H372-H377.

5. Werns SW, Shea MJ, Lucchesi BR. Free radicals and myocardial injury: pharmacologic implications. Circulation 1986;74:1-5.

6. Jarasch ED, Grund C. Bruder G, Ficid HW, Kcenan TW, Frankc W'W Localization of xanthine oxidase in mammary-gland epithelium and capillary endothelium. Cell 1981:25:67-82.

7. McCord IM. Oxygen-derived free radicals in pustischemic tissue injury. $N$ Engl J Med 1985;312:159-163.

8. Reimer KA, Hill ML, Jennings RB. Prolonged depletion of the adenine nucleotide pool due to delayed resynthesis of adenine nucleotides following reversible myocardial ischemic injury in dogs. $J \mathrm{Mol}$ Cell Cardiol 1981:[3:229-239.

9. Corr PB, Gross RW, Sobel BE. Amphipathic metabolites and membrane dysfunction in ischemic myocardium. Circ Res 1984:55:135-154.

10. Slater TF. Free radical mechanisms in tissue injury. Biochem J 1984;222:1-5. 11. Dianzani MU. Biochemical effects of saturated and unsaturated aldehydes. In: McBrien DCH, Slater TF, eds. Free Radicals, Lipid Peroxidation and Cancer. London and New York: Academic Press, 1982:129-158.

12. Esterbauer H. Lipid peroxidation products: formation, chemical properties and biological activities. In: Poli G, Cheeseman KV, Dianzani MU, Slater TF, eds. Free Radicals in Liver Injury. Oxford, England, and Washington, D.C.: IRL Press, 1987:29-47.

13. Serruys PW, Wijns W, Van den Brand MJBM, Mey S, Slager C, Schuurbiers JCH. Hugenholtz PG, Brower RW. Left ventricular performance, regional blood flow, wall motion and lactate metabolism during transluminal angioplasty. Circulation 1984;70:25-36.

14. Harmsen E, De Jong JW, Serruys PW. Hypoxanthine production by isch- emic heart demonstrated by high pressure liquid chromatography of blood purine nucleosides and oxypurines. Clin Chim Acta 1981:111:73-84.

15. Huizer T, De Jong JW, Nelson JA, Czarnecki W, Serruys PW, Bonnier JJRM, Troquay R. Urate production by human heart. $J \mathrm{Mol}$ Cell Cardiol 1989:21:691-695

16. Serruys $P W$, Suryapranalia $H$, Piscione F, Harmsen E. Van den Brand M, De Feyter PJ, Hugenholtz PG, De Jong JW. Myocardial release of hypoxanthine and lactate during percutaneous transluminal coronary angioplasty. Am J Cardiol 1989:63:45E-51E.

17. Huizer T, De Jong JW, Achterberg PW. Protection by bepridil agains myocardial adenosine triphosphate-catabolism is probably due to negative inotropy. J Cardiouasc Pharmacol 1987;10:55-61.

18. Jackson MJ, Jones DA, Edwards RHT. Lipid peroxidation of skeletal muscle: an in vitro study. Biosci Rep 1983;3:609-618.

19. Santos MT, Valles J, Aznar J, Vilches J. Determination of plasmamalondialdehyde-like material and its clinical application in stroke patients. J Clin Pathol 1980;33:973-976

20. Aznar J, Santos MT, Valles J, Sala J. Serum malondialdehyde-like material (MDA-LM) in acute myocardial infarction. $J$ Clin Pathol 1983;36:712-715.

21. Sato Y. Hotta N. Sakamoto N, Matsouka S. Ohishi N. Yagi K. Lipid peroxide levels in plasma of diabetic patients. Biochem Med 1979;21:104-107. 22. Knight JA, Pieper RK, McClelian L. Specificity of the thiobarbituric acid reaction: its use in studies of lipid peroxidation. Clin Chem 1988;34:2433-2438. 23. Aust SD. Lipid peroxidation. In: Greenwauld RA, ed. CRC Handbook of Methods for Oxygen Radical Research. London: CRC Press, 1985:203-207. 24. Oldroyd KG, Chopra M, Rankin $\Lambda$ C. Belch JJF, Cobbe SM. Lipid peroxidation during myocardial ischaemia induced by pacing. Br Heart $J$ 1990;63:88-92 25. Lewis DH, Del Maestro RF. Free radicals in medicine and biology. Acta Physiol Scand Suppl 1980,492:1-168.

26. Jewett SL, Eddy LJ, Hochstein P. Is the autoxidation of catecholamines involved in ischemia-reperfusion injury? Free Radic Biol Med 1989;6:185-188. 27. Simpson PJ, Lucchesi BR. Free radicals and myocardial ischemia and reperfusion injury. $J$ Lab Clin Med 1987;110:13-30.

28. Rosson RD, Swain JL, Michael LH, Weakley S, Giannini E, Entman ML. Selective accumulation of the first component of complement and leukocytes in ischemic canine heart muscle. A possible initiatior of an extra-myocardial mechanism of ischemic injury. Circ Res 1985:57:119-130.

29. Bolli R. Bharat SP. Jeroudi MO, Lai EK, McCay PB. Demonstration of free radical generation in "stunned" myocardium of intact dogs with the use of the spin trap $\alpha$-phenyl $\mathrm{N}$-tert-butyl nitrone. J Clin Invesi 1988:82:476-485.

30. Burrell CJ, Blake DR. Reactive oxygen metabolites and the human myocardium. Br Heart $J$ 1989:61:4-8

31. De Jong JW. Keijzer F, Huizer T, Schoutsen B. Ischemic nuclentide hreakdown increases during cardiac development due to drop in adenosine anabolism/ catabolism ratio. $J$ Mol Cell Cardiol 1990;22:1065-1070.

32. Terada LS, Beehler CJ, Banerjee A, Brown JM, Grosso MA, Harken AH McCord JM, Repine JE. Hyperoxia and self - or neutrophil-generated O2 metabolites inactivate xanthine oxidase. $J$ Appl Physiol 1988:65:2349-2353.

\title{
Waking Up Exhausted as Risk Indicator of Myocardial Infarction
}

\author{
Ad Appels, PhD, and Erik Schouten
}

$\mathrm{D}$ uring the last decade several studies have indicated that sleep problems might belong to the risk indicators for coronary artery disease (CAD). For example, a 6-year follow-up study of $>10,000$ subjects revealed a risk of 2.04 for CAD in "poor" versus "good" sleepers. ${ }^{1}$ Little is known about the types of sleep complaints that are associated with future CAD. One may speculate that trouble falling asleep is

From the Department of Medical Psychology, University of Limburg, Box 616, $6200 \mathrm{MD}$ Maastricht, the Netherlands. This study was supported by Grant 83.069 of the Dutch Heart Foundation, The Hague. Manuscript received November 13, 1990; revised manuscript received and accepted March 25, 1991. associated with CAD, because this is indicative of prolonged tension. Trouble staying asleep may be predictive for the same reason, or because it is indicative of a heart failure or nocturnal angina. Waking up tired may reflect an impaired sleep or an adverse effect of medication, angina pectoris or aging, and lose its predictive power when adjusted for these factors.

Waking up tired may also indicate depression. Recent meta-analyses of the vast literature of personality factors and CAD have shown that, of all personality attributes, depression is the one most strongly associated with disease outcome. ${ }^{2}$ Because early-morning tiredness is a major characteristic of depression it is predicted that prob- 